\title{
Minimal laminectomy using the interlaminar approach for percutaneous endoscopic lumbar discectomy
}

\author{
Hisashi Koga ${ }^{1,2}$, Hirohiko Inanami ${ }^{1,2}$ \\ ${ }^{1}$ Department of Orthopaedics, Iwai Orthopaedic Medical Hospital, 8-17-2 Minamikoiwa, Edogawa-ku, Tokyo 133-0056, Japan. \\ ${ }^{2}$ Department of Orthopaedic Surgery, Inanami Spine and Joint Hospital, 3-17-5 Higashishinagawa, Shinagawa-ku, Tokyo 140-0002, Japan.
}

Correspondence to: Dr. Hisashi Koga, Department of Orthopaedics, Iwai Orthopaedic Medical Hospital, 8-17-2 Minamikoiwa, Edogawa-ku, Tokyo 1330056, Japan. E-mail: hkoga0808@gmail.com

How to cite this article: Koga $\mathrm{H}$, Inanami H. Minimal laminectomy using the interlaminar approach for percutaneous endoscopic lumbar discectomy. Mini-invasive Surg 2017;1:56-62.

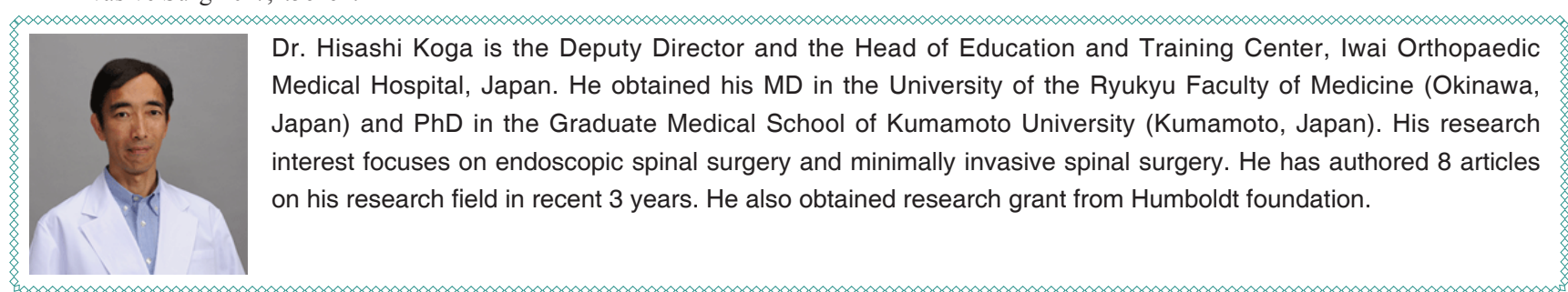

Article history:

Received: $18-02-2017$

Accepted: 26-02-2017

Published: 30-06-2017

Key words:

Percutaneous endoscopic lumbar discectomy,

lumbar disc herniation, interlaminar approach, minimal laminectomy, minimally invasive

\section{INTRODUCTION}

Percutaneous endoscopic lumbar discectomy (PELD)

\section{ABSTRACT}

\begin{abstract}
Aim: To evaluate the application of laminectomy using the interlaminar approach (ILA) for percutaneous endoscopic lumbar discectomy (PELD). Methods: Minimal laminectomy using the ILA for PELD was performed in 13 patients with lumbar disc herniation (LDH). The width of the interlaminar space, shape of the caudal margin of the upper vertebral laminae (CM-UVL), LDH size, and caudal migration grade were radiologically evaluated. Ten LDHs were removed via the shoulder of the corresponding nerve root, and three via the axilla of the corresponding nerve root and dural sac. Bone status was evaluated preoperatively and postoperatively using two- and three-dimensional computed tomography. Results: All patients (mean age 46.3 years) underwent PELD at a single spinal level, mostly at L5/S1. Compared with a previous study without laminectomy, the mean operative duration $(57.5 \mathrm{~min}$ ) and operative outcome, evaluated using the modified Japanese Orthopaedic Association and Numerical Rating Scale scores, were similar; no complications were observed. However, the width of the interlaminar space was significantly narrower, and eight cases revealeda narrow interlaminar space (width $<$ $20 \mathrm{~mm}$ and/or lost concave shape of CM-UVL). Conclusion: Minimal laminectomy using the ILA for PELD is feasible for treating LDH with the narrow space and highly migrated LDH.
\end{abstract}

is one of the most sophisticated operative procedures for the treatment of lumbar disc herniation $(\mathrm{LDH}) \cdot{ }^{[1-5]}$ However, PELD has an anatomical limitation for

\section{(c) (i)}

This is an open access article licensed under the terms of Creative Commons Attribution 4.0 International License (https://creativecommons.org/licenses/by/4.0/), which permits unrestricted use, distribution, and reproduction in any medium, as long as the original author is credited and the new creations are licensed under the identical terms.

For reprints contact: service@oaepublish.com

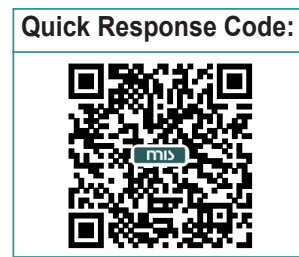


endoscope insertion, and there are three different operative approaches: interlaminar, transforaminal, and posterolateral. Each approach has an adequate pathophysiological status..$^{[1,6,7]}$ The interlaminar approach (ILA) is preferred for axillary-type and migrated $\mathrm{LDH}{ }^{[1]}$ It is performed under endoscopic visualization, and the visual field is similar to conventional open and/ or microsurgical operative views. Therefore, the ILA is preferred by surgeons with experience in performing conventional procedures, rather than other PELD

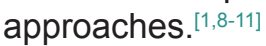

Conversely, we have previously experienced and reported on relatively severe complications of the ILA. ${ }^{8]}$ These complications included persistent numbness in the corresponding nerve area, transient muscular weakness, and transient bladder and rectal disturbance, which may be due to excessive compression of the nerve root and/or dural sac by the endoscopic sheath. As a result of these experiences, we have been more careful in performing the ILA and have not experienced such complications. To avoid complications, we proposed the proper use of 2 different operative routes of the ILA (via the shoulder and via the axilla). Furthermore, we suggested that the width of the interlaminar space should be at least $20 \mathrm{~mm}$ for the ILA without bone removal. ${ }^{[8]}$

We sometimes experience cases in which the width of the interlaminar space is $<20 \mathrm{~mm}$ even in LDH at $\mathrm{L} 5 / \mathrm{S} 1 .^{[1]}$ To overcome this limitation, we recently started to use a high-speed drill and/or a small Kerrison rongeur (width $3 \mathrm{~mm}$ ) for certain ILA cases. We have already experienced 13 such cases and avoided complications. In this study, we retrospectively analyzed these cases, and summarized the features of minimal laminectomy with the ILA.

\section{METHODS}

Thirteen consecutive patients with LDH underwent the ILA for PELD by using a 7-mm diameter spinal fullendoscopic system (Richard Wolf $\mathrm{GmbH}$, Knittlingen, Germany) between March and December 2016. All patients had lateral radiculopathy resistant to medical treatment, epidural steroids, and/or nerve block. To clarify the surgical benefit of minimal laminectomy with the ILA for PELD, we did not exclude patients who previously underwent discectomy at the same vertebral level. However, we excluded patients with spinal canal stenosis who had been operated on using the percutaneous endoscopic translaminar approach. ${ }^{[12]}$

All patients underwent the ILA for PELD at only one vertebral level. Neurological examination, preoperative computed tomography (CT), and magnetic resonance imaging (MRI) were used to identify the location and type of LDH according to our previous report. ${ }^{[8]}$ The width of the interlaminar space and the LDH size were calculated on axial CT and MRI, respectively, as described previously [the width was determined by the widest distance between the bilateral facet joints at the corresponding disc level, and the LDH size was evaluated by the anteroposterior (AP) size ratio calculated from the protruded height against the AP diameter of the spinal canal]..$^{[8]}$ The extent of migration was evaluated by using T2-weighted sagittal MRI according to previous reports. ${ }^{[13,14]}$ High-grade migration was defined as migration exceeding the disc-space height. Conversely, low-grade migration was defined as a migration extent that was smaller than the disc-space height [Figure $1 \mathrm{~A}$ and $\mathrm{B}$ ].

The patients were followed postoperatively for an average of 6.2 months (2-11 months). Neurological status was evaluated preoperatively and postoperatively by using the modified Japanese Orthopaedic Association (mJOA) score. ${ }^{[15,16]}$ The corresponding leg pain was also evaluated by using the Numerical Rating Scale (NRS) score. ${ }^{[17]}$ We compared data for these parameters with our previous ILA data [laminectomy (-) group: 41 cases]. Statistical analysis was performed with student's $t$-test. $P$ values $<0.05$ were considered statistically significant. The exclusion of high-grade caudal migration is the differentiated background of the laminectomy (-) group.

In addition to these previous parameters, we also evaluated the shape of the upper vertebral laminae. Concave (-) was defined as when the caudal margin of the upper vertebral laminae (CM-UVL) was straight and the interlaminar space appeared as a sharp triangle. Concave $(+)$ was defined as when the CM-UVL had a concave shape and the interlaminar space appeared to have a more rounded form [Figure $1 \mathrm{C}$ and $\mathrm{D}$ ].

The basic operative procedure has already been described in our previous report. ${ }^{[0]}$ In addition to the basic ILA procedure, the methods for manipulation of a high-speed drill and/or a small Kerrison rongeur are described below.

First, the endoscope sheath is placed on the surface of the yellow ligament and then tilted toward a direction by which the area requiring bone removal is at the center of the endoscopic visual field. The vertebral laminae are thinned by using a high-speed drill with a diameter of $3.5 \mathrm{~mm}$ (NSK-Nakanishi Japan, Tokyo, Japan). Subsequently, the residual thin layer is removed with a small Kerrison rongeur. Naturally thin bone areas, such as the inner border of the superior articular process 
(SAP), are directly removed by using the Kerrison rongeur. In such cases, after detachment of the yellow ligament from the bone margin, the cutting edge of the Kerrison rongeur is sledded into the detached space (case 4, Supplementary Video 1). As exposure of a small part of the protruded vertebral disc is sufficient to remove it, we only perform minimum removal of bone and yellow ligament (final stage of Supplementary Video 1: the white protruded disc surface at the shoulder area of the nerve root can be seen).

\section{RESULTS}

Thirteen patients were registered for this study; 10 underwent the ILA via the shoulder (cases 1-10) and three underwent the ILA via the axilla (cases 11-13). The mean patient age was 46.3 years (range 17-82 years), and the most affected vertebral level was L5/ S1 (11 cases), followed by L4/5 (2 cases). The LDH location, AP size ratio, width of the interlaminar space, operation time, postoperative hospital stay, blood loss, and operative outcome (mJOA and NRS scores) for each case are shown in Table 1. Compared with our previous ILA data[laminectomy (-) group], the width of the interlaminar space in the cases that received laminectomy was significantly narrower $(25.95 \mathrm{~mm}$ vs. $22.46 \mathrm{~mm}, P=0.003)$. However, there was no significant difference between the 2 groups in the AP size ratio, operation time, postoperative hospital stay, blood loss, follow-up period, and operative outcome. We observed no intraoperative complications in this study [Table 1].

Two recurrent cases (cases 1 and 5) received minimal laminectomy for exposure of the fresh margin of the vertebral laminae and yellow ligament. One case (case 2) received minimal laminectomy to perform ILA underan inappropriate endoscope insertion due to a high level of obesity (body mass index 39.4). Generally, the endoscope is introduced from the caudal to the cephalic direction toward the interlaminar space; however, we could not maintain this slope because of the thickness of soft tissue in this case. We had to remove the CM-UVL, which is one workaround for inappropriate endoscope insertion.

Furthermore, we radiologically analyzed each case that received laminectomy, including the shape of the upper vertebral laminae, extent of migration, and area of laminectomy [Table 2].

Four of 10 cases (cases 4, 6, 9, and 12) showed an interlaminar space with a width of $<20 \mathrm{~mm}$, and a small extent of SAP removal was mainly required. The
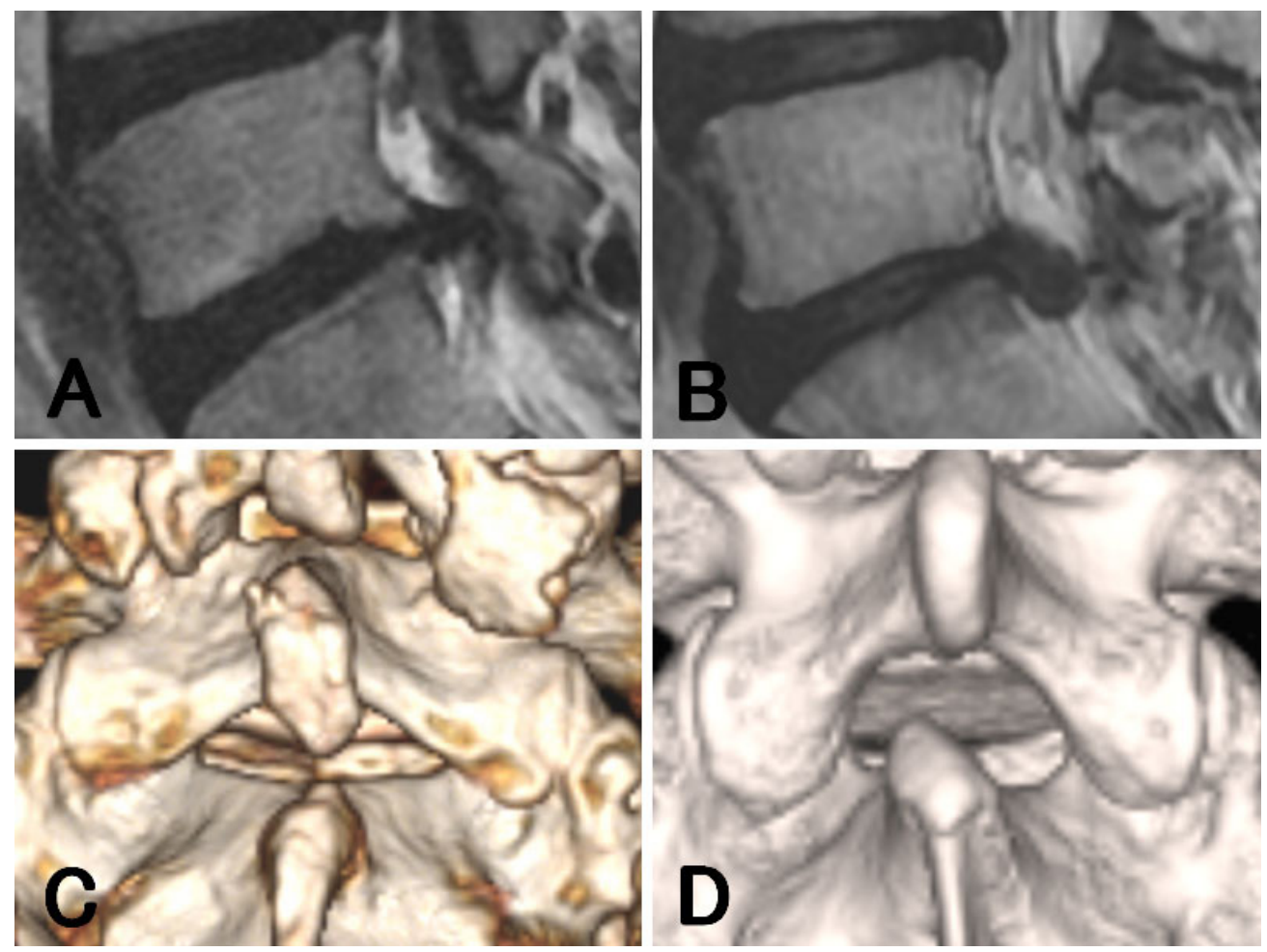

Figure 1: Preoperative radiographic findings on the migration and shape of the upper vertebral laminae. The extent of migration was evaluated by using T2-weighted sagittal magnetic resonance imaging. (A) Low-grade migration: defined as a migration extent smaller than the height of the disc space (case 2); (B) high-grade migration: defined as a migration extent exceeding the height of the disc space (case 11); (C) concave (-): caudal margin of the upper vertebral laminae (CM-UVL) is straight, as evaluated by using three-dimensional computed tomography (case 8); (D) concave (+): CM-UVL has a measurable concave and the superior articular process is easy to access (case 9) 
preoperative and postoperative radiological changes in case 6, in which we only removed the SAP $4 \mathrm{~mm}$ toward the lateral direction, are shown in Figure 2. Six of 10 cases (cases $3,4,7,8,10$, and 12) lost the concave shape of the upper vertebral laminae. Among these, two cases (cases 4 and 12) also showed an interlaminar space with a width of $<20 \mathrm{~mm}$. The preoperative and postoperative radiological changes in case 12, in which we removed the SAP and cephalic margin of the lower vertebral laminae and completely removed the highly migrated nucleus, are shown in Figure 3. Taken together, a total of eight of 10 cases required minimal laminectomy for a narrow interlaminar space evaluated by using the width and shape.

The remaining two cases underwent ILA via the axilla.

Table 1: Comparative surgical outcome of 41 cases without laminectomy ${ }^{[8]}$ and 13 cases with laminectomy

\begin{tabular}{|c|c|c|c|c|}
\hline \multicolumn{2}{|c|}{ Laminectomy* } & $(-) \ddagger$ & $(+)$ & $P$ value \\
\hline \multicolumn{2}{|l|}{ Total cases } & 41 & 13 & \\
\hline \multicolumn{2}{|l|}{ Age (years) } & 41.5 & 46.3 & 0.260 \\
\hline \multirow[t]{2}{*}{ Gender } & Male & 25 & 11 & \\
\hline & Female & 16 & 2 & \\
\hline \multirow[t]{3}{*}{ Level } & $\mathrm{L} 4 / 5$ & 7 & 2 & \\
\hline & $\mathrm{L} 5 / 6 \dagger$ & 1 & 0 & \\
\hline & L5/S1 & 23 & 11 & \\
\hline \multirow[t]{2}{*}{$R / L$} & Right & 19 & 5 & \\
\hline & Left & 22 & 8 & \\
\hline \multirow[t]{4}{*}{ Type of MRI } & Shoulder & 8 & 1 & \\
\hline & Ventral & 19 & 10 & \\
\hline & Axilla & 10 & 2 & \\
\hline & Central & 4 & 0 & \\
\hline \multicolumn{2}{|c|}{ AP size ratio (MRI) } & 0.44 & 0.44 & 0.962 \\
\hline \multicolumn{2}{|c|}{ Width of interlaminal space } & 25.95 & 22.46 & 0.003 \\
\hline \multicolumn{2}{|c|}{ Operation time (min) } & 50.7 & 57.5 & 0.211 \\
\hline \multicolumn{2}{|c|}{ Postoperative hospital stay (days) } & 2.1 & 2 & 0.803 \\
\hline \multicolumn{2}{|l|}{ Blood loss } & Negligible & Negligible & \\
\hline \multicolumn{2}{|c|}{ Follow-up period (months) } & 9.2 & 6.2 & 0.064 \\
\hline \multirow[t]{2}{*}{ mJOA score } & Preoperative & 10.6 & 12.7 & 0.211 \\
\hline & Postoperative & 18.6 & 18 & 0.610 \\
\hline \multirow[t]{2}{*}{ NRS score } & Preoperative & 5.83 & 5.46 & 0.632 \\
\hline & Postoperative & 1 & 1.77 & 0.098 \\
\hline \multicolumn{2}{|l|}{ Complication } & 3 & 0 & \\
\hline
\end{tabular}

MRI: magnetic resonance imaging; AP: anteroposterior; mJOA: modified Japanese Orthopaedic Association scale; NRS: numerical rating scale; (-) previous data; $(+)$ current data. ${ }^{*}(+)$ Indicates lumbar disc herniation $(\mathrm{LDH})$ case received minimal laminectomy and (-) indicates $\mathrm{LDH}$ cases did not receive minimal laminectomy; †lumbarization of the first sacral segment was designated as L6; $\neq$ this data is cited from ${ }^{[8]}$
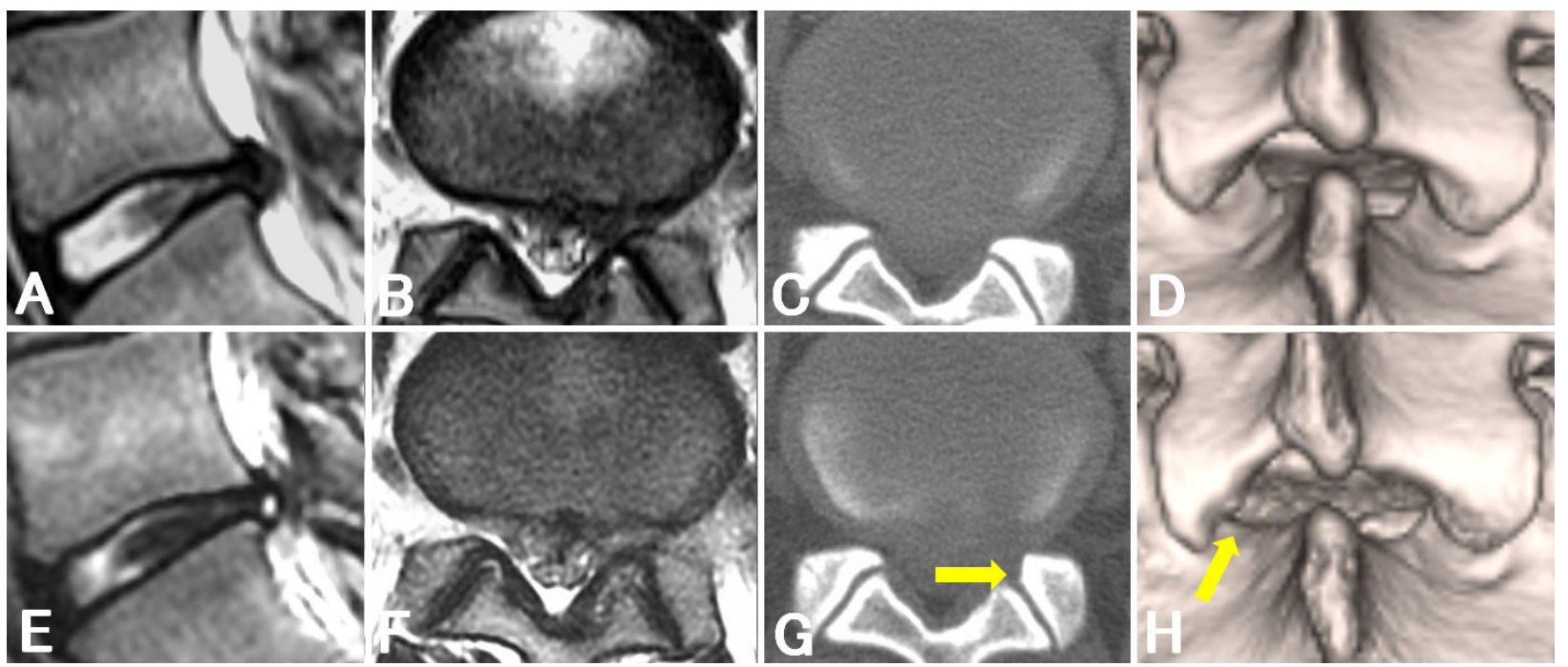

Figure 2: Magnetic resonance imaging and computed tomography findings of a patient with subligamentous lumbar disc herniation (case 6). Preoperative (A, B) and postoperative (E, F) sagittal $(A, E)$ and axial $(B, F)$ T2-weighted magnetic resonance images. Preoperative (C, D) and postoperative $(G, H)$ axial $(C, G)$ and three-dimensional $(D, H)$ computer tomographic images: arrows indicate the margin of minimal laminectomy 


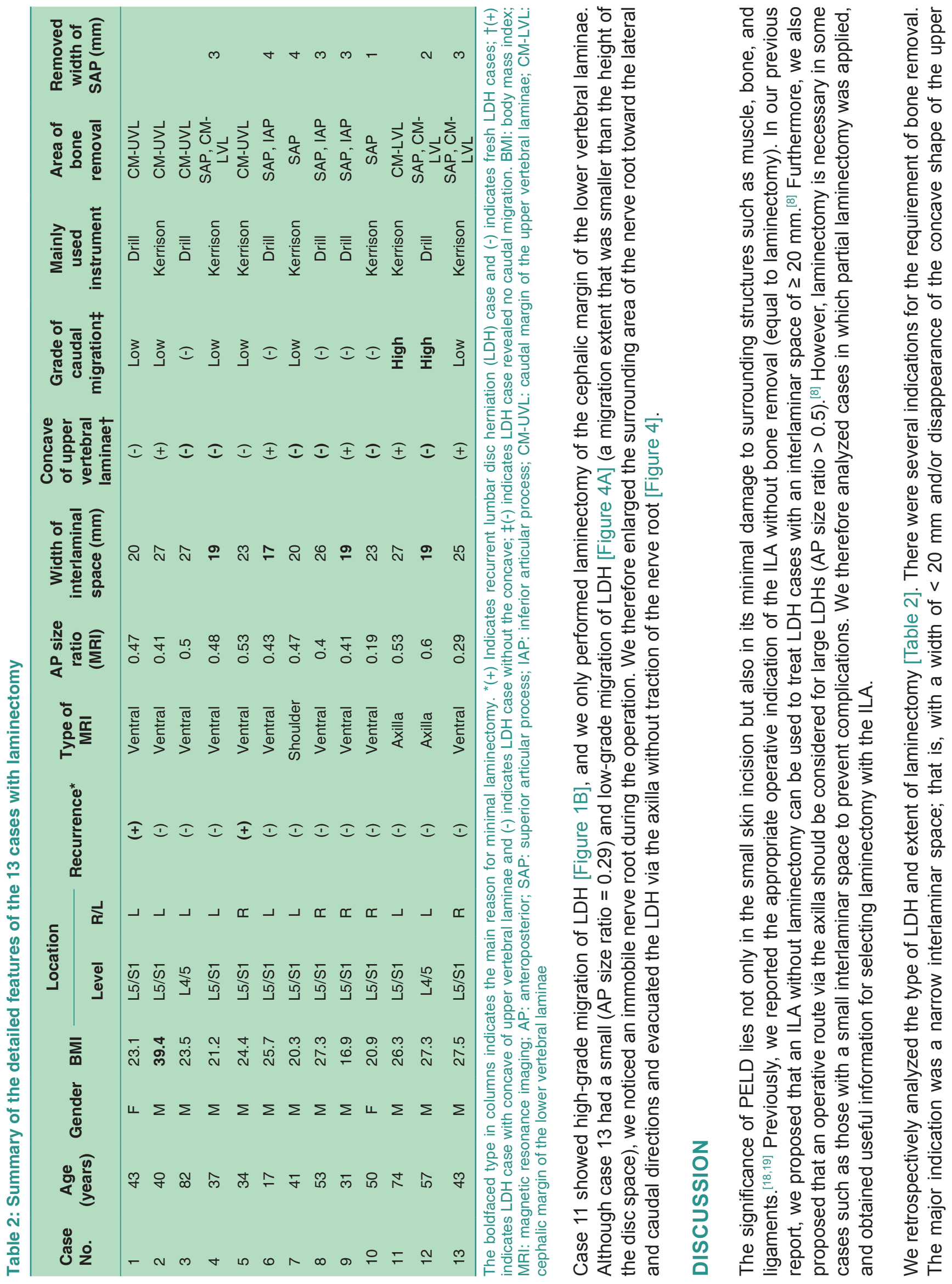




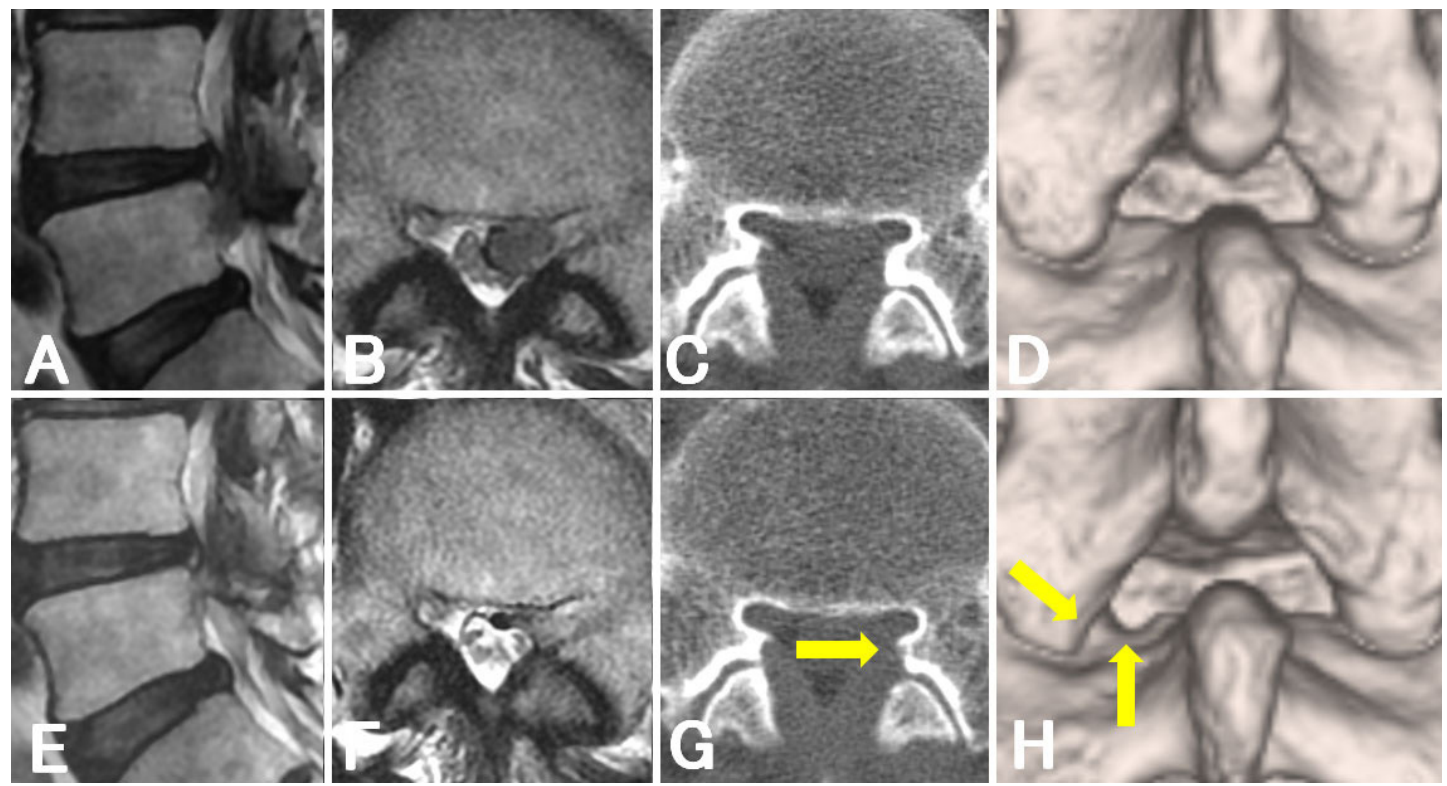

Figure 3: Magnetic resonance imaging and computed tomography findings of a patient with high-grade migration of lumbar disc herniation (case 12). Preoperative (A, B) and postoperative (E, F) sagittal (A, E) and axial (B, F) T2-weighted magnetic resonance images. Preoperative $(C, D)$ and postoperative $(G, H)$ axial $(C, G)$ and three-dimensional $(D, H)$ computer tomographic images: arrows indicate the margin of minimal laminectomy
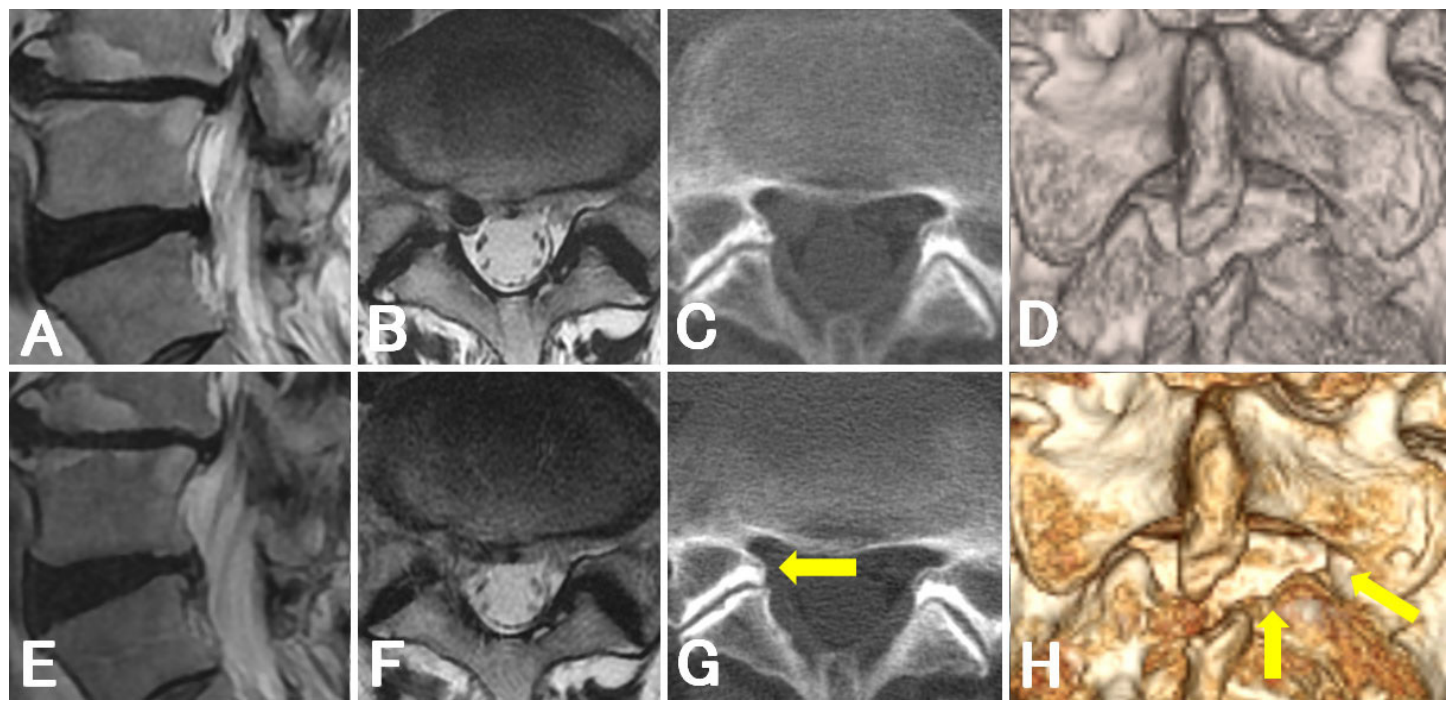

Figure 4: Magnetic resonance imaging and computed tomography findings of a patient with an immobile nerve root (case 13). Preoperative $(A, B)$ and postoperative $(E, F)$ sagittal $(A, E)$ and axial $(B, F)$ T2-weighted magnetic resonance images. Preoperative (C, D) and postoperative $(G, H)$ axial $(C, G)$ and three-dimensional $(D, H)$ computer tomographic images: arrows indicate the margin of minimal laminectomy

vertebral laminae. In these cases, the inner border of the SAP was a main target for laminectomy. In concave (-) cases, removal of the straight CM-UVL was occasionally required. In cases with high-grade migration, the lateral part of the cephalic margin of the lower vertebral laminae was the main target. In addition to the narrow interlaminar space and highgrade migration of $\mathrm{LDH}$, minimal laminectomy was also useful in cases showing recurrent LDH, obesity, or an immobile nerve root.

A high-speed drill is necessary for the laminectomy of the CM-UVL, because the bone here is thick. However, it is not always necessary to remove the bone of the inner border of the SAP and the cephalic margin of the lower vertebral laminae by using a high-speed drill, because the bone here is thin. In such cases, a small Kerrison rongeur is a powerful tool for laminectomy. Furthermore, PELD allows for removal of the inner margin of the SAP without removing the inferior articular process [Supplementary Video 1]. Around $3 \mathrm{~mm}(1-4 \mathrm{~mm}$, average $2.9 \mathrm{~mm}$ ) of laminectomy of the SAP toward the outside was enough to expose the protruded LDH and the lateral margin of the nerve root. Compared with 
conventional surgeries such as open, microscopic, and microendoscopic discectomy, the extent of bone removal in the ILA is extremely small. Removal of the yellow ligament to this small extent is also sufficient in the ILA for PELD.

In conclusion, the preliminary results of a small number of cases show that minimal laminectomy with the ILA for PELD is feasible for the treatment of LDH with a narrow interlaminar space and high-grade migration. Furthermore, minimal laminectomy is also useful for cases showing recurrent LDH, obesity, or an immobile nerve root.

\section{Authors' contributions}

\section{Conception and design: $\mathrm{H}$. Koga}

Provision of study materials or patients: $\mathrm{H}$. Koga, $\mathrm{H}$. Inanami

Collection and assembly of data: H. Koga

Data analysis and interpretation: $\mathrm{H}$. Koga

Manuscript writing: $\mathrm{H}$. Koga

Final approval of manuscript: H. Koga, H. Inanami

\section{Acknowledgments}

We thank all the operating room staff for their technical assistance, and the medical records clerks who helped collect patient data. We also thank all radiological department staff for accumulating CT and MRI data.

\section{Financial support and sponsorship}

This work was partly supported by a grant from the Iwai Medical Foundation.

\section{Conflicts of interest}

The authors have no conflicts of interest to declare.

\section{Patient consent}

Informed consent was obtained from the patients for publication of this study and any accompanying images.

\section{Ethics approval}

This study was approved by the ethics committee of the Iwai Medical Foundation.

\section{REFERENCES}

1. Choi KC, Kim JS, Ryu KS, Kang BU, Ahn Y, Lee SH. Percutaneous endoscopic lumbar discectomy for L5-S1 disc herniation: transforaminal versus interlaminar approach. Pain physician 2013; 16:547-56.

2. Sairyo K, Egawa H, Matsuura T, Takahashi M, Higashino K, Sakai T, Suzue N, Hamada D, Goto T, Takata Y, Nishisho T, Goda Y, Sato R, Tsutsui T, Tonogai I, Kondo K, Tezuka F, Mineta K, Sugiura K,
Takeuchi M, Dezawa A. State of the art: transforaminal approach for percutaneous endoscopic lumbar discectomy under local anesthesia. $J$ Med Invest 2014;61:217-25.

3. Yeung AT. The evolution and advancement of endoscopic foramina surgery: one surgeon's experience incorporating adjunctive technologies. SAS J 2007;1:108-17.

4. Hirano Y, Mizuno J, Takeda M, Itoh Y, Matsuoka H, Watanabe K. Percutaneous endoscopic lumbar discectomy -- early clinical experience. Neurol Med Chir (Tokyo) 2012;52:625-30.

5. Nellensteijn J, Ostelo R, Bartels R, Peul W, van Royen B, van Tulder M. Transforaminal endoscopic surgery for symptomatic lumbar disc herniations: a systematic review of the literature. Eur Spine $J$ 2010;19:181-204.

6. Yokosuka J, Oshima Y, Kaneko T, Takano Y, Inanam H, Koga $\mathrm{H}$. Advantages and disadvantages of posterolateral approach for percutaneous endoscopic lumbar discectomy. J Spine Surg 2016;2:158-66.

7. Lee S, Kim SK, Lee SH, Kim WJ, Choi WC, Choi G, Shin SW. Percutaneous endoscopic lumbar discectomy for migrated disc herniation: classification of disc migration and surgical approaches. Eur Spine J 2007;16:431-7.

8. Tonosu J, Oshima Y, Shiboi R, Hayashi A, Takano Y, Inanami H, Koga H. Consideration of proper operative route for interlaminar approach for percutaneous endoscopic lumbar discectomy. J Spine Surg 2016;2:281-8.

9. Zekaj E, Menghetti C, Saleh C, Isidori A, Bona A, Aimar E, Servello D. Contralateral interlaminar approach for intraforaminal lumbar degenerative disease with special emphasis on L5-S1 level: a technical note. Surg Neurol Int 2016;7:88.

10. Choi G, Prada N, Modi HN, Vasavada NB, Kim JS, Lee SH. Percutaneous endoscopic lumbar herniectomy for high-grade downmigrated L4-L5 disc through an L5-S1 interlaminar approach: a technical note. Minim Invasive Neurosurg 2010;53:147-52.

11. Kim CH, Chung CK, Jahng T-A, Yang HJ, Son YJ. Surgical outcome of percutaneous endoscopic interlaminar lumbar diskectomy for recurrent disk herniation after open diskectomy. J Spinal Disord Tech 2012;25:E125-33.

12. Dezawa A, Mikami H, Sairyo K. Percutaneous endoscopic translaminar approach for herniated nucleus pulposus in the hidden zone of the lumbar spine. Asian J Endosc Surg 2012;5:200-3.

13. Lee SH, Kang BU, Ahn Y, Choi G, Choi YG, Ahn KU, Shin SW, Kang HY. Operative failure of percutaneous endoscopic lumbar discectomy: a radiologic analysis of 55 cases. Spine (Phila Pa 1976) 2006;31:E285-90

14. Lee SH, Choi KC, Baek OK, Kim HJ, Yoo SH. Percutaneous endoscopic intra-annular subligamentous herniotomy for large central disc herniation: a technical case report. Spine (Phila Pa 1976) 2014;39:E473-9.

15. Oshima Y, Takeshita K, Inanami H, Takano Y, Koga H, Iwahori T, Baba $\mathrm{S}$, Tanaka S. Cervical microendoscopic interlaminar decompression through a midline approach in patients with cervical myelopathy: a technical note. J Neurol Surg A Cent Eur Neurosurg 2014;75:474-8.

16. Baba $\mathrm{S}$, Oshima $\mathrm{Y}$, Iwahori $\mathrm{T}$, Takano $\mathrm{Y}$, Inanami $\mathrm{H}$, Koga $\mathrm{H}$. Microendoscopic posterior decompression for the treatment of thoracic myelopathy caused by ossification of the ligamentum flavum: a technical report. Eur Spine J 2016;25:1912-9.

17. Hartrick CT, Kovan JP, Shapiro S. The numeric rating scale for clinical pain measurement: a ratio measure? Pain Pract 2003;3:310-6.

18. Singh K, Ledet E, Carl A. Intradiscal therapy: a review of current treatment modalities. Spine (Phila Pa 1976) 2005;30:S20-6.

19. Birkenmaier C, Komp M, Leu HF, Wegener B, Ruetten S. The current state of endoscopic disc surgery: review of controlled studies comparing full-endoscopic procedures for disc herniations to standard procedures. Pain Physician 2013;16:335-44. 